\title{
Médiévales
}

Langues, Textes, Histoire

56 | printemps 2009

Pratiques de l'écrit

\section{Céline BALASSE, 1306. L'expulsion des juifs du royaume de France, Bruxelles, De Boeck, 2008, 392 p.}

\section{Claire Soussen}

\section{(2) OpenEdition}

\section{Journals}

Édition électronique

URL : https://journals.openedition.org/medievales/5609

DOI : $10.4000 /$ medievales.5609

ISSN : 1777-5892

\section{Éditeur}

Presses universitaires de Vincennes

\section{Édition imprimée}

Date de publication : 30 juin 2009

Pagination : 179-181

ISBN : 978-2-84292-232-0

ISSN : 0751-2708

\section{Référence électronique}

Claire Soussen, «Céline BALASSE, 1306. L'expulsion des juifs du royaume de France, Bruxelles, De Boeck 2008, 392 p. », Médiévales [En ligne], 56 | printemps 2009, mis en ligne le 21 septembre 2009, consulté le 22 avril 2022. URL : http://journals.openedition.org/medievales/5609 ; DOI : https://doi.org/ 10.4000/medievales.5609

Ce document a été généré automatiquement le 22 avril 2022.

Tous droits réservés 


\title{
Céline BALASSE, 1306. L'expulsion des juifs du royaume de France, Bruxelles, De Boeck, 2008, 392 p.
}

\author{
Claire Soussen
}

1 Pourquoi Philippe le Bel, souverain secret, a-t-il décidé d'expulser les juifs du royaume de France au mois de juin 1306 ? Cette interrogation guide le propos de Céline Balasse, qui retrace les différentes étapes du processus et surtout donne à l'événement une profondeur chronologique, spatiale, économique et politique. Ce livre est le fruit du remaniement de la thèse de Doctorat de l'auteure, soutenue en juin 2006. Si l'épisode est régulièrement évoqué dans les ouvrages qui traitent du règne de Philippe le Bel ou de la construction du royaume de France, les mobiles qui l'ont sous-tendu sont souvent rapidement analysés. Cela s'explique sans doute parce qu'un certain nombre d'énigmes demeurent autour de cette affaire, que $\mathrm{C}$. Balasse décide malgré tout d'éclairer grâce à la documentation dont elle dispose. Celle-ci se compose pour l'essentiel des archives de la Chancellerie royale (registres et layettes du Trésor des Chartes), de l'Inventaire des Comptes royaux, des Journaux du Trésor de Philippe le Bel, des Actes du parlement de Paris, et des Registres des arrêts rendus par la Cour du roi.

2 L'enquête s'articule autour de quatre parties d'inégale importance. La première (47 pages) retrace "L'évolution pluriséculaire des politiques juives " jusqu'au règne de Philippe le Bel. Elle rappelle les grandes orientations des autorités spirituelles (bulles Sicut Iudeis favorables aux juifs à partir de 1120 et Turbato Corde instituant la méfiance à leur égard en 1267) et temporelles à l'égard des juifs en Chrétienté et signale leur durcissement à partir de la fin du XII ${ }^{e}$ siècle, autour notamment des campagnes contre la pratique de l'usure impulsées par Philippe Auguste et saint Louis.

3 La deuxième partie (65 pages) «L'expulsion de 1306 : études locales » nous fait entrer dans le vif du sujet. C. Balasse entreprend de retracer le cours des événements, dont beaucoup d'épisodes restent incertains. Première inconnue: le document officiel portant ordre d'expulser les juifs du royaume de France a disparu. Les chroniques et les documents de la pratique l'évoquent fréquemment, mais ne donnent pas de version 
convergente du déroulement des faits. D'après les chroniques, l'expulsion se serait produite en une journée, alors que les documents portant remboursement de leurs frais aux agents royaux chargés de l'arrestation et de l'évaluation des biens des juifs laissent entrevoir une durée bien plus longue des opérations (près de trois mois pour la seule arrestation). Il est d'ailleurs possible que les documents portant arrestation des juifs du royaume n'aient pas mentionné l'hypothèse de leur expulsion pour éviter l'évasion financière. L'arrestation aurait eu pour objectif le recensement des biens des juifs ; leur expulsion n'aurait figuré dans la documentation que dans un second temps. Deuxième inconnue: le nombre de personnes concernées. L'estimation du nombre de juifs résidant dans le royaume de France sous Philippe le Bel est difficile à réaliser et le chiffre généralement retenu est celui de 100 000, auquel l'auteur se range.

4 Rassemblant les "pièces du puzzle", C. Balasse propose la chronologie suivante: l'opération de saisie débute le 21 juin 1306 ; la date officielle de sortie semble (l'édit a été perdu) avoir été fixée au 22 juillet 1306 ; les actes de vente des biens des juifs sont promulgués entre la fin juillet et la mi-août 1306 et les enchères sont conclues entre la fin août 1306 et le 23 septembre 1311. Quant au recouvrement des dettes, il constituait la partie la plus complexe de l'opération puisqu'il supposait une enquête auprès des débiteurs des juifs expulsés. Les livres de compte parfois laissés par ces derniers, n'étaient en effet pas exploitables par les agents royaux dans la mesure où ils étaient rédigés en hébreu. De ce fait, les débiteurs chrétiens pouvaient à loisir mentir sur le montant des sommes dues aux juifs. Par ailleurs, un certain nombre des agents chargés de tirer ces affaires au clair, furent convaincus de détournement de biens et d'argent des juifs. Ces dérives s'étant révélées difficilement surmontables, Philippe le Bel autorisa temporairement les prêteurs juifs à revenir pour renseigner l'administration fiscale, avant d'imposer leur départ définitif en 1311. Signe de sa complexité et de son caractère stratégique, le travail de recouvrement des dettes se poursuit jusqu'au milieu des années 1320. Ce sont précisément ces deux éléments (malhonnêteté de certains responsables des opérations et processus de recouvrement des dettes), qui ouvrent sur les deux questions sans doute les plus intéressantes de l'ouvrage: la mise en perspective politique et la mise en perspective économique de l'entreprise de Philippe le Bel. Depuis le début de son règne, celui-ci s'était attaché à imposer la théorie selon laquelle il détenait «la propriété des juifs du royaume » (p. 68). La confrontation avec les seigneurs dont les terres abritaient des juifs, faisait donc bien de cette opération un enjeu politique. L'auteur renvoie cette question dans une troisième partie analytique et consacre l'essentiel du reste de sa deuxième partie à l'étude locale et minutieuse de l'expulsion (chapitre 6).

5 La troisième partie (113 pages) «L'expulsion de 1306: une analyse globale de l'événement» dresse le bilan humain, financier et politique de l'opération. Cent quatorze personnes au minimum sont intervenues à un moment ou à un autre de l'expulsion, soit un dixième de l'administration royale entre 1306 et 1314. Les trois quarts étaient de hauts officiers de la couronne qui supervisèrent l'arrestation et l'organisation de la spoliation. C. Balasse retrace notamment l'itinéraire professionnel des «commissaires aux affaires des juifs » et montre que si leur implication ne leur a pas valu de promotion particulière, en revanche ils ont été choisis parce que l'on connaissait leurs compétences dans les affaires financières. Le quart restant des personnes impliquées était des notables locaux qui se chargèrent de la vente des biens, du recouvrement des dettes et de la gestion des recettes sur le long terme. 
6 L'analyse de la façon dont les biens des juifs ont été vendus et surtout de leur mise sur le marché selon un étalement stratégique, ainsi que le fait que le roi, plutôt que d'annuler les contrats en cours, ait choisi de les faire honorer par les débiteurs des juifs expulsés, montre le profit financier que la royauté attendait de l'opération. Cependant, la récupération des sommes d'argent par « un roi devenu créancier » ne fut pas chose facile. Les nombreuses difficultés survenues (la question des gages; de l'argent déposé par des chrétiens pour que les juifs le fassent travailler; de l'argent dû par des juifs à des chrétiens) mettent en évidence la complexité et la richesse des relations entre juifs et chrétiens, qui ne peuvent se résumer à une dépendance financière unilatérale. La manière forte fut choisie dans un premier temps et les débiteurs contraints de rembourser leurs dettes au roi. Toutefois les comptes n'étaient pas soldés à la mort de Philippe le Bel, et le recouvrement se poursuivit jusqu'au milieu des années 1320 . C. Balasse donne une estimation du produit de la confiscation des biens des juifs : entre 109250 livres tournois (estimation basse) et 116500 livres tournois (estimation haute) au total pour la période courant de la fin 1306 à la fin 1311, soit un revenu moyen de plus de 20000 livres tournois par an, somme nettement supérieure aux revenus annuels tirés sur les juifs du domaine royal en temps normal. D'après ces chiffres, à terme, le roi était donc gagnant. Il le fut peut-être encore davantage, symboliquement, dans la rivalité qui l'opposait aux seigneurs. La confiscation des biens des juifs et leur expulsion de tout le royaume et pas seulement du domaine royal, montre la victoire du roi dans sa politique de confiscation de la tutelle sur les juifs. Malgré quelques réclamations, le règlement des contentieux aboutit au constat selon lequel tous les juifs étaient juifs du roi et que celui-ci avait sur eux une autorité supérieure à celle des seigneurs.

7 La quatrième partie (66 pages), "À la recherche des motifs de l'expulsion ", passe en revue, de façon un peu artificielle, les différents motifs possibles de l'opération. La démonstration a, pour l'essentiel, déjà été faite, et de manière tout à fait convaincante, dans la troisième partie. C. Balasse écarte donc logiquement les motifs religieux, et revient sur les enseignements des expulsions précédentes, qu'on s'attendrait à trouver plus tôt dans l'ouvrage. En revanche l'interrogation à laquelle elle soumet l'hypothèse de la pression populaire comme élément moteur de la décision royale permet, en l'invalidant, de rappeler que pour beaucoup de chrétiens, les emprunts réalisés auprès des juifs étaient nécessaires. L'auteure cite la chronique de Geoffroi de Paris qui assure "que la population regrette très amèrement leur départ » (p. 277). Autre preuve, pour l'auteure, de l'invalidité de l'hypothèse : aucune violence n'a accompagné l'expulsion des juifs.

8 C. Balasse retrouve donc les deux motifs préalablement avancés : en expulsant les juifs de son royaume et en confisquant leurs biens, Philippe le Bel entendait réaliser un profit économique ; par ailleurs, en imposant aux seigneurs son autorité supérieure sur les juifs, il affirmait la supériorité de l'autorité royale sur les prétentions seigneuriales. $\mathrm{Au}$ terme de son enquête, $\mathrm{C}$. Balasse répond de façon tout à fait convaincante à la question soulevée au début de son livre. Partant, elle fait œuvre utile et donne enfin les éclairages nécessaires à une affaire souvent évoquée sans qu'elle eût reçu les attentions qu'elle méritait. 